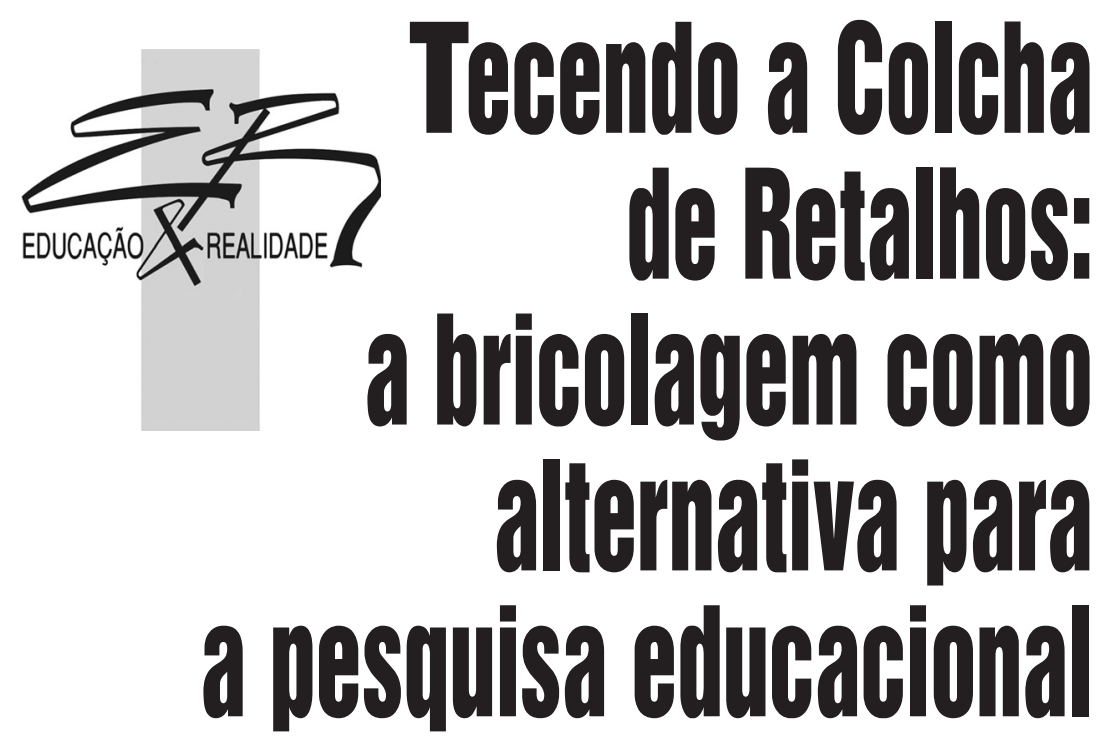

\author{
Marcos Garcia Neira \\ Bruno Gonçalves Lippi
}

RESUMO - Tecendo a Colcha de Retalhos: a bricolagem como alternativa para a pesquisa educacional. A intensidade das mudanças sociais em curso colocou em xeque o legado da modernidade. As verdades elaboradas pela ciência moderna têm sofrido fortes abalos. Até mesmo o modo de produzir conhecimentos é questionado nos tempos atuais. Dentre as alternativas emergentes, encontra-se a bricolagem. Os bricoleurs apelam para uma variedade de métodos, instrumentos e referenciais teóricos que lhes possibilitem acessar e tecer as interpretações de diferentes origens. Impulsionados pelos Estudos Culturais, denunciam as relações de poder que influenciam os discursos científicos postos em circulação. O presente artigo discute os pressupostos e procedimentos metodológicos e oferece um exemplo de uma pesquisa educacional inspirada na bricolagem.

Palavras-chave: Pesquisa. Bricolagem. Interpretação.

ABSTRACT - Crafting the Patchwork: bricolage as an alternative for educational research. The intensity of the current social changes has confronted the modernity legacy. The truths produced by the modern science have been under strong uncertainties. Even the way to produce knowledge is questioned nowadays. Amongst the emerging alternatives, there is the bricolage. The bricoleurs use a variety of methods, instruments and theoretical references that make possible to access and build interpretations from various places. Driven by the Cultural Studies, denounce the relationship of power that influence the scientific speeches put in course. The present article discusses the presumptions and methodological procedures, and offers an example of educational research inspired in the bricolage.

Keywords: Reasearch. Bricolage. Interpretation.

Educ. Real., Porto Alegre, v. 37, n. 2, p. 607-625, maio/ago. 2012.

Disponivel em: <http://www.ufrgs.br/edu_realidade> 


\section{O Contexto}

Pós-modernidade, modernidade líquida, hipermodernidade, modernidade tardia: são várias as expressões que procuram definir o atual momento político, econômico, social e cultural. Diversas análises evidenciam que a sociedade transformou-se significativamente nas últimas cinco décadas. Entre outros aspectos, as inovações tecnológicas tornaram-se preponderantes na vida cotidiana. Celulares, computadores, softwares e redes virtuais de comunicação influem diretamente na hibridização de hábitos, costumes, formas de se relacionar, levando-nos a questionar os pilares que sustentam a sociedade ocidental.

Tantas modificações acabaram por afetar a racionalidade científica. $\mathrm{Na}$ modernidade, a ciência positivista constituiu-se como alicerce da verdade. A razão era vista como entidade capaz de garantir um curso unitário da história em direção a uma sociedade plenamente desenvolvida, justa e igualitária. Concebida como uma entidade superior, a ciência foi dotada de características metafísicas como neutralidade e imparcialidade. Nela, foram depositadas as esperanças para solução dos problemas enfrentados pela humanidade.

Todavia, as transformações em curso na contemporaneidade vêm conferindo limites à racionalidade científica positivista. Silva (1996), entre tantos outros, vai afirmar que a ciência não é a solução para os problemas do mundo, pelo contrário, pertence ao problema, pois também se trata de um discurso. Em tempos pós-modernos, o questionamento da ciência abre espaço para aceitação de outros referenciais para a explicação do mundo, quer seja pelas mudanças nos critérios e procedimentos empregados na sua produção ou pelo reconhecimento da validade de outros discursos como a religião, mitologia e senso comum (Sousa Santos, 2001).

Na contemporaneidade, outros referenciais são empregados para interpretar a realidade e produzir conhecimentos válidos. Sob esse ponto de vista, o espectro do sujeito autônomo e emancipado alardeado pela modernidade ruiu, pois todos nos encontramos envoltos em um emaranhado de significados culturais que constituem nossas identidades sociais (Hall, 1997), inviabilizando tanto a alienação quanto a emancipação. Trata-se de uma análise a partir dos Estudos Culturais, campo teórico que compreende a identidade como produto de uma construção discursiva.

Nelson, Treichler e Grossberg (2008) definem os Estudos Culturais como um termo de conveniência para uma gama bastante dispersa de posições teóricas e políticas. Sinteticamente, partilham o compromisso de examinar as práticas culturais do ponto de vista de seu envolvimento com, e no interior de relações de poder. Giroux (2008, p. 98) compreende os Estudos Culturais como "[...] o estudo da produção, da recepção e do uso situado de variados textos, e da forma como eles estruturam as relações sociais, os valores e as noções de comunidade, o futuro e as diversas definições do eu". No campo da educação, Costa, Silveira e Sommer (2003) apontam como contribuições mais importantes desse campo 
teórico a desnaturalização dos discursos instalados no meio educacional, além da ampliação e complexificação do debate sobre os processos de subjetivação.

A partir dos Estudos Culturais, qualquer faceta do fenômeno pedagógico poderá ser imaginada sob o modelo da textualidade. Enquanto texto, a educação abrange práticas, estruturas institucionais e complexas formas de atividade, que requerem condições legais e políticas de existência, determinados fluxos de poder e conhecimento, bem como uma organização semântica específica. Simultaneamente, esse texto só existe dentro de uma rede de relações intertextuais (a rede textual da cultura mais ampla, da cultura escolar, da cultura docente etc.). Trata-se de uma entidade ontologicamente mista e para a qual não pode haver nenhuma forma privilegiada de leitura (Frow; Morris, 2006). É justamente isso, mais do que qualquer outra coisa, que força a atenção para as investigações educacionais baseadas nos Estudos Culturais. Afinal, sua recusa em desvincular qualquer prática social das políticas do poder, reforça a ideia de que não se podem ignorar os fatores que interferem na definição dos significados e das metas da educação.

Os Estudos Culturais fornecem subsídios para afirmar o caráter político da educação. Incitam uma investigação mais rigorosa que analise os processos de identificação/diferenciação travados no seu interior. Para os Estudos Culturais, revelar os mecanismos pelos quais se constroem determinadas representações ${ }^{1}$ é o primeiro passo para reescrever os processos discursivos e alcançar a formação de outras identidades (Nelson; Treichler; Grossberg, 2008).

No campo da pesquisa, os Estudos Culturais apelam a qualquer perspectiva teórico-metodológica que colabore para produzir o conhecimento exigido. Nelson, Treichler e Grossberg (2008) consideram que essa metodologia, “[...] ambígua desde o início, pode ser mais bem entendida como uma bricolagem. Isto é, sua escolha da prática é pragmática, estratégica e autoreflexiva" (p. 09). Os autores julgam problemática a adoção acrítica das práticas disciplinares formalizadas pela academia, pois carregam uma herança de investimentos, exclusões e uma história de efeitos sociais que os Estudos Culturais repudiam. Por essa razão, Frow e Morris (2006) sugerem a utilização da análise textual, a recorrência a diversas fontes e a utilização eclética de variados métodos e técnicas de pesquisa. Ao questionarem as formas positivistas de produzir conhecimento, os Estudos Culturais valorizam “o ato de 'situar' objetos particulares para análise" (p. 321) e apelam a múltiplas leituras de mundo para compreender como se constroem as representações atribuídas a qualquer prática cultural.

A opção pela bricolagem busca dar coerência aos posicionamentos político e epistemológico que inspiram a análise cultural, pois, os Estudos Culturais consideram difícil, senão impossível, provocar transformações e mudanças nos quadros sociais sem que sejam modificadas ou alteradas as estruturas e hierarquias que regem a produção dos conhecimentos científicos.

Diante da pequena frequência de pesquisas educacionais que empregam a bricolagem, o presente artigo objetivou chamar a atenção para sua viabilidade. O caminho adotado consistiu no levantamento da literatura disponível sobre o 
tema, na explicitação dos seus argumentos principais e, a fim de ilustrar esse processo investigativo, foi apresentado um breve relato de pesquisa.

\section{A Bricolagem}

Oriundo do francês, o termo bricolage significa um trabalho manual feito de improviso e que aproveita materiais diferentes. $\mathrm{Na}$ apropriação realizada por Lévi-Strauss (1976), o conceito de bricolagem foi definido como um método de expressão através da seleção e síntese de componentes selecionados de uma cultura. Por sua vez, relendo o trabalho do antropólogo, Derrida (1971) ressignificou o termo no âmbito da teoria literária, adotando-o como sinônimo de colagem de textos numa dada obra. Finalmente, De Certeau (1994) utilizou a noção de bricolagem para representar a união de vários elementos culturais que resultam em algo novo.

No campo da pesquisa educacional, Kincheloe (2006) seguiu um raciocínio semelhante ao definir a bricolagem como um modo de investigação que busca incorporar diferentes pontos de vista a respeito de um mesmo fenômeno. Em trabalho posterior, Kincheloe (2007) ampliou essa definição ao dizer que bricolagem é uma forma de fazer ciência que analisa e interpreta os fenômenos a partir de diversos olhares existentes na sociedade atual, sem que as relações de poder presentes no cotidiano sejam desconsideradas. Adotando uma postura ativa, a bricolagem rejeita as diretrizes e roteiros preexistentes, para criar processos de investigação ao passo em que surgem as demandas.

A bricolagem permite que as circunstâncias deem forma aos métodos empregados. Sua existência é explicada a partir de uma epistemologia da complexidade (Morin, 2002), cujo propósito é manter a confluência da pesquisa moderna e pós-moderna e alimentar os discursos conflitantes entre elas sem delimitar fronteiras conceituais ou o predomínio de uma sobre a outra. Na bricolagem, explica Kincheloe (2007), nenhum método pode ser privilegiado ou empregado com segurança, tampouco descartado antecipadamente.

Ao respeitar os diversos olhares e experiências que permeiam a sociedade multicultural contemporânea, a bricolagem altera a lógica dominante na produção de conhecimentos. Efetivamente, almeja romper com o reducionismo, o parcelamento, a fragmentação e a neutralidade científica dos métodos positivistas, os quais legitimam as relações de poder desiguais (Kincheloe, 2007).

$\mathrm{Na}$ bricolagem não se busca descobrir verdades, como se elas estivessem escondidas à espera de um investigador, o que se pretende é entender a sua construção e questionar como os diversos agentes sociais produzem e reproduzem o que é imposto pelos discursos hegemônicos. Ora, teorias e conhecimentos nada mais são do que artefatos culturais e linguísticos. Uma vez que a interpretação está imbricada na dinâmica social e histórica que moldou o artefato cultural sob análise, a bricolagem reconhece a inseparabilidade entre objeto de pesquisa e contexto. Consequentemente, a linguagem e as relações de poder 
assumem a posição central nas interpretações da realidade, pois se constituem como mediadores fundamentais na contemporaneidade.

Diferentemente da pesquisa positivista, na bricolagem a subjetividade e o posicionamento político não são descartados. Construir conhecimentos a partir de múltiplas vozes exige saber qual a origem das explicações fornecidas e quais experiências sociais influenciam os olhares sobre o fenômeno investigado. $\mathrm{Ou}$ seja, é preciso ouvir diversas explicações sobre o objeto para que o pesquisador possa percorrer inúmeros caminhos, aproximar-se e, talvez, chegar a múltiplas interpretações.

Tanto a interpretação de fenômenos sociais quanto a construção de conhecimentos são campos de luta simbólicos disputados pelos grupos culturais que tentam fazer prevalecer suas concepções. Não obstante, o discurso da neutralidade é pura ingenuidade de alguns e esperteza de outros, que apostam nesse artifício para garantir a hegemonia. Advém daí a necessidade da multiplicidade de vozes no desenrolar da pesquisa, principalmente daquelas marginalizadas, bem como da explicitação do posicionamento político e epistemológico do pesquisador.

O rigor de uma pesquisa inspirada na bricolagem se afirma na consciência da consulta à diversidade de posições (Kincheloe, 2007). O conhecimento produzido é assumidamente provisório e processual, pois se reconhece a existência de diversas interpretações sobre o objeto, edificadas por meio de discursos e construções sociais.

Apesar de sua multilogicidade, fazer bricolagem implica selecionar métodos, estratégias e referenciais teóricos. O bricoleur, nas palavras de Denzin e Lincoln (2006, p. 18), é "um indivíduo que confecciona colchas [...] que utiliza as ferramentas estéticas e materiais do seu ofício, empregando efetivamente quaisquer estratégias, métodos ou materiais empíricos que estejam ao seu alcance". "A escolha das práticas de pesquisa depende das perguntas que são feitas, e as perguntas dependem do seu contexto" (Nelson; Treichler; Grossberg, 2008, p. 09).

Dentre os vários tipos de bricoleurs, o interpretativo coaduna plenamente com os princípios teórico-metodológicos dos Estudos Culturais. O bricoleur interpretativo produz representações que se encaixam nas especificidades de uma situação complexa. O resultado “[...] é uma construção que sofre mudanças e assume novas formas à medida que se acrescentam diferentes instrumentos, métodos e técnicas de representação e interpretação" (Denzin; Lincoln, 2006, p. 18). O bricoleur interpretativo entende que a pesquisa é um processo interativo influenciado pela história pessoal, biografia, gênero, classe social e etnia, dele e daquelas pessoas que fazem parte do cenário investigado. O produto final é um conjunto de imagens mutáveis e interligadas. 


\section{Entretecendo Interpretações}

$\mathrm{O}$ ato interpretativo na bricolagem deve promover o desvendar de significados e sentidos expressos pelos diferentes sujeitos. Para compreender como os diversos grupos constroem suas interpretações da realidade, Kincheloe (2007, p. 102) recomenda hermenêutica crítica como forma de análise. A hermenêutica é crítica no sentido de que se dedica a um diálogo com a tradição da teoria crítica.

A teoria crítica está sempre preocupada com as formas como o poder opera as maneiras com que várias instituições e interesses mobilizam o poder no esforço para sobreviver, moldam o comportamento, adquirem dominação sobre os outros ou, num viés mais produtivo, aprimoram a condição humana .

A teoria crítica entende que os seres humanos são produtos históricos do poder. Homens e mulheres não emergem fora do processo da história, suas identidades são moldadas pelos inter-relacionamentos nas teias do poder. A hermenêutica crítica emerge no diálogo entre a hermenêutica e a preocupação da teoria crítica com o poder e a ação social (McLaren, 2000).

$\mathrm{Na}$ tradição hermenêutica, a pesquisa qualitativa é interpretativa. "Em sua articulação mais elementar, o ato hermenêutico da interpretação envolve o entendimento daquilo que foi observado de forma a comunicar a compreensão" (Kincheloe; McLaren, 2006, p. 287). O ato hermenêutico implica em produzir descrições densas dos textos sociais considerando seu contexto de produção, as intenções dos seus produtores e os significados mobilizados nos processos de sua construção. A finalidade da análise hermenêutica é desenvolver uma forma de crítica cultural que revele as dinâmicas do poder dentro dos textos sociais e culturais. $\mathrm{O}$ trabalho do pesquisador consiste em, expressam ainda as autoras, construir "[...] pontes entre o leitor e o texto, o texto e quem o produz, o contexto histórico e a atualidade, e uma determinada circunstância social e outra" (Kincheloe; McLaren, 2006, p. 288).

Ao invés de reprimir a subjetividade, a interpretação baseada na hermenêutica crítica busca entendê-la dentro do processo de construção de valores e saberes sobre o objeto de investigação. $\mathrm{O}$ ato interpretativo deve acontecer a partir de relações entre o indivíduo e as questões emergentes do ambiente macrossocial. Para entender porque os sujeitos constroem determinadas representações e não outras, os Estudos Culturais fornecem o aporte necessário.

Na bricolagem as interpretações sempre são entretecidas (Kincheloe, 2007). Entretecer significa vamos tecer juntos, tecer entremeando. O uso da palavra não é aleatório, tampouco estético, mas, de fato, intencional. $\mathrm{O}$ ato de entretecer fundamenta uma concepção de pesquisa que pretende construir a partir de uma perspectiva crítica, questionadora, dialógica e dialética. Tecer juntos, entremeando, almeja uma produção coletiva de conhecimentos, respeitadora de múltiplas perspectivas e que contemple o ir e vir, o relativo, o temporário e o imprevisível da complexidade contemporânea. 
O entretecer configura-se a partir da multiplicidade de vozes e do seu alinhavar, compreendendo de qual local partem os discursos e quais grupos atuam em sua defesa. Mediante o entretecimento ou a tessitura de diferentes posicionamentos, a bricolagem rompe com a arrogância de uma interpretação unívoca da prática social em foco para favorecer a emergência de outras interpretações.

Para entretecer as representações sobre o objeto de estudo, o pesquisador procura ouvir os sujeitos, conhecer suas visões e compreender os pressupostos que sustentam seus argumentos. Cada participante do estudo é convidado a interpretar as representações dos demais envolvidos: pares e pesquisador. A bricolagem incita, justamente, o encontro das interpretações dos sujeitos com as interpretações de quem faz a pesquisa.

O entretecimento, explica Berry (2007), parte de um texto como porta de entrada, doravante denominado POETA (do original POET, abreviatura de Point Of Entry Text), que se constitui como a primeira aproximação do fenômeno estudado. O POETA ou texto inicial é algo que possa produzir sentido na investigação: uma reportagem, uma poesia, uma imagem, um filme, uma sala de aula, um debate eleitoral, um livro, uma teoria, um depoimento, um diálogo etc. O POETA, que representa um discurso sobre um fenômeno social, deve ser analisado e interpretado a partir de múltiplos olhares. A rota é sempre aleatória e imprevisível. O POETA é tão somente a largada. Funciona como um ponto de origem através do qual os posicionamentos serão entretecidos.

O POETA deve ser constantemente realimentado por diversas explicações sobre o objeto. É a amplitude de análises efetuadas que garantirá a validade e o rigor científico da pesquisa. "O texto original é alterado em conteúdo e em estrutura, uma vez que o volume de entretecimentos aumenta a cada realimentação" (Berry, 2007, p. 131). Durante a realimentação, o POETA é submetido a múltiplas leituras, discursos conflitantes, ideologias divergentes e posicionamentos políticos antagônicos, numa tentativa de contemplar as diferenças. As interpretações incorporadas ao POETA devem ser novamente confrontadas. Esse movimento de colocar em xeque as interpretações é um recurso importante para depurar as análises.

$\mathrm{Na}$ bricolagem, não existe explicação verdadeira, conclusão do estudo ou considerações finais, pois, o conhecimento é transitório e está sempre em processo. É impossível produzir uma explicação completa sobre determinado fenômeno social, pois a complexa natureza das relações embutidas em qualquer situação não permite que isso aconteça. Por conseguinte, a bricolagem é uma produção de conhecimentos que não se finaliza, segue um processo contínuo de realimentação e entretecimento.

Kincheloe (2007, p. 112) ratifica essa ideia ao afirmar que "[...] todas as descrições do mundo são uma interpretação e sempre há novas interpretações a serem encontradas". Todavia, quando o que se pretende é construir uma sociedade menos desigual e democrática, na qual todas as pessoas se sintam representadas e ouvidas, não se pode descansar enquanto não sejam identifica- 
das e socializadas, em todos os espaços disponíveis, as diferentes perspectivas sobre um mesmo fato.

\section{A Bricolagem em uma Pesquisa Educacional}

A partir dos pressupostos teórico-metodológicos que subsidiam a bricolagem na investigação qualitativa, o estudo de Lippi (2009) analisou as representações acerca do programa de formação contínua de professores denominado "A rede aprende com a rede"2", implementado pela Secretaria da Educação do Estado de São Paulo (SEE/SP) durante os anos 2008 e 2009. Para tanto, foram entrelaçadas as interpretações dos pontos de vista dos personagens ${ }^{3}$ envolvidos, das videoaulas utilizadas e das matérias jornalísticas que abordavam a política educacional paulista.

Ressalte-se que os Estudos Culturais não reconhecem posicionamentos individuais (Silva, 2006). Os participantes do estudo não emitiram posicionamentos autônomos. O mesmo pode ser dito dos conteúdos das videoaulas e dos textos midiáticos. Eles influenciavam e eram influenciados pelas esferas sociais as quais pertenciam. Colocavam discursos em circulação, assim como os acessavam.

O primeiro passo foi entrevistar um assessor pedagógico da CENP ${ }^{4}$. A partir de perguntas abertas sobre temas relacionados à política formativa, $\mathrm{o}$ profissional posicionou-se com relação às diretrizes, intenções, concepções de professor, trabalho pedagógico, escola e destacou o que, em sua opinião, seriam os aspectos positivos, negativos, avanços e retrocessos. A fala do profissional foi gravada e transcrita. Os trechos considerados principais foram extraídos para composição de uma narrativa de duas páginas: o POETA.

Em seguida, retomando o construto dos Estudos Culturais, o pesquisador buscou compreender quais discursos contemporâneos influenciavam as representações do entrevistado. $\mathrm{O}$ foco recaiu no entendimento do contexto pós-moderno e sua intersecção com a economia neoliberal. Ganhou visibilidade a influência do neoliberalismo na política educacional em vigor na SEE/SP. Essas interpretações foram incorporadas ao POETA.

Em 2008, deu-se a elaboração e implementação da proposta curricular. Dentro da proposta curricular, os cadernos dos professores procuravam dar sugestões de como trabalhar os conteúdos com base nas habilidades e competências selecionadas pelos elaboradores da proposta. No primeiro semestre, esses materiais chegaram e os professores tiveram contato com eles para começar a entendê-los. Por causa das dúvidas, no segundo semestre, criou-se o curso "A rede aprende com a rede". Destaque-se que a construção da proposta curricular influenciou significativamente a política de formação contínua de professores. Já que temos um currículo comum, devemos formar nossos professores para atuar dentro de um determinado modelo curricular. A produção de propostas curriculares é uma invenção daqueles que defendem um formato neoliberal 
para educação escolar. Ou seja, ela é um instrumento tecnicista que auxilia quem deseja ter o controle e o gerenciamento sobre os conteúdos e os processos de ensino. Este controle burocrático e centralizado pode estar a serviço de outros interesses, como por exemplo, a legitimação de conhecimentos importantes para a formação de mão de obra para determinados setores do mercado de trabalho, resgatando, com algumas alterações, os princípios que vigoravam na década de $1970^{5}$.

Além do assessor da CENP, cuja transcrição do depoimento deu início à tessitura, participaram do estudo: um representante da Secretaria de Educação, dois membros da equipe gestora de uma escola, uma professora; um representante do sindicato dos professores; um jornalista de um veículo de comunicação de grande circulação; e uma pesquisadora de políticas educacionais.

Seguindo as recomendações de Kincheloe (2006) e de Denzin e Lincoln (2006), a escolha dos participantes não foi aleatória. O pesquisador buscou um equilíbrio quantitativo entre representantes da rede de ensino e membros externos; setores que tradicionalmente se posicionam a partir de ideias progressistas e conservadoras; além de indivíduos alocados em diferentes níveis da hierarquia administrativa. A opção por entrevistar um jornalista especializado na área deveu-se, segundo o investigador, à pressão exercida pela imprensa paulista na época para a implantação de medidas que resultassem na melhoria dos índices alcançados pelas escolas públicas nas avaliações oficiais. Setores da mídia atribuíam o baixo desempenho à qualidade dos docentes.

O segundo sujeito leu excertos do POETA previamente selecionados pelo pesquisador, realizou suas análises e teceu os comentários sobre as interpretações do pesquisador, bem como às falas do participante que o antecedeu. Esse procedimento foi repetido após cada intervenção dos sujeitos. O POETA foi realimentado e entretecido com as interpretações dos sujeitos e do pesquisador, crescendo em tamanho e complexidade. Na sua última versão, a narrativa alcançou a dimensão de sessenta e oito páginas.

Observe-se que as entrevistas não seguiram uma estrutura rígida, prevaleceu o diálogo para favorecer a narrativa. Narrar significa voltar ao passado e reconstruir a própria história, atribuindo-lhe sentido (Larrosa, 2006). Por meio do estabelecimento da relação entre fatos e histórias, constroem-se significados. É o que permite interpretar a realidade.

A seleção dos excertos do POETA baseou-se no pressuposto de que, ao falar de lugares sociais distintos, os participantes emitiriam posicionamentos divergentes acerca das ações que envolviam a formação contínua de professores, o que propiciaria o confronto de ideias que caracteriza a bricolagem (Berry, 2007). O embate provocado aprofundou a compreensão dos argumentos que sustentavam os discursos proferidos pelos defensores ou críticos da política oficial.

O assessor da CENP, questionado sobre os conteúdos do programa "A rede aprende com a rede", respondeu: "Os professores têm grandes dificuldades 
em lidar com o processo de ensino-aprendizagem pautado em habilidades e competências". Na interpretação do pesquisador, essa fala reverbera a acusação da formação docente deficitária como responsável pelo fracasso escolar. Uma vez que o discurso da incompetência é veementemente contestado pelas entidades sindicais, a fala do assessor foi incorporada ao POETA, provocando a seguinte reação no sindicalista:

É verdade, também, que a apropriação desses conceitos de competência e habilidade serviram para dizer qualquer coisa sem nenhuma rigorosidade, como dizia Paulo Freire [...] Isso é armadilha, sobretudo, para as classes populares, aquelas que não detêm os meios de produção. Só a partir da educação, do avanço científico, da capacidade de autonomia e de liberdade que você pode mudar a sociedade de classes. [...] Eu concordo que a geração de professores de hoje tem uma grande dificuldade de trabalhar com esses conceitos e que pese também que eu acho que eles são contraditórios, eles permitem que você possa ter uma cobrança rebaixada desses mesmos níveis de conteúdos que se voltam contra a própria classe, mantendo-a dirigida e não dirigente. Considero os conceitos importantes. Se você considerar como os conteúdos podem estabelecer relações, mas acho que, no fundo, ele são dois 'nomezinhos' para legitimar uma política de rebaixamento curricular.

Outra participante do estudo, uma pesquisadora de políticas educacionais, após a leitura do que disse o assessor e o representante sindical, emitiu seu posicionamento sobre o assunto. Segundo ela, o discurso das competências embute a irrelevância dos conteúdos. Em outras palavras, o critério de seleção de conteúdos ampara-se no princípio que o conteúdo, independente de sua origem cultural, serve quando mobiliza alguma competência ou habilidade valorizada pelo currículo central. Ela afirmou que o debate competências/ habilidades versus conteúdos não tem fundamento e indagou: "[...] como se formam competências e habilidades sem conteúdos?" Na sua visão, trata-se de uma falácia que serve como forma de precarizar e minimizar o trabalho na escola pública.

O agrupamento dos excertos de acordo com o tema abordado impediu a tergiversação das falas dos participantes. Para estimular uma postura reflexiva, cada entrevistado foi instigado a partir de recortes do POETA que apresentavam posicionamentos antagônicos. No momento das entrevistas, a autoria das falas não era comunicada aos participantes. $\mathrm{O}$ cuidado deveu-se à necessidade de garantir que a interpretação se concentrasse prioritariamente no discurso proferido.

Em seus comentários sobre a responsabilidade pela formação contínua de professores, a diretora escolar afirmou:

Eu tenho que correr atrás, eu sou professor [...] esse é conteúdo desse ano que eu elegi, eu tenho que ensinar, o que eu preciso fazer para ensinar, eu preciso estudar mais, eu preciso trocar experiências com outros colegas, eu preciso fazer um mestrado. Como é que você não é responsável pela sua formação individual? Você precisa se aprimorar o tempo todo. 
O jornalista compartilhou da proposta e fez sugestões: A formação deve demandar certo esforço do professor, pois é a mesma demanda de uma pessoa que trabalha em uma empresa privada e vai fazer um MBA. Vai ter que estudar fora do horário, vai buscar um monte de coisas, vai ter sacrifício como qualquer profissional que queira fazer uma formação diferente, queira se aprimorar. Se a formação oferecida pela SEE/SP é de baixa qualidade, o sindicato poderia oferecer cursos de capacitação aos professores.

Contrapondo-se às colocações dos seus antecessores, o representante sindical rebateu:

Correr atrás' [da formação], reproduz o 'self made man', é uma ideia típica do capitalismo. Na minha opinião, o poder público deve prever a formação em serviço. Há pessoas que dizem que o sindicato não é lugar para ter formação. Todavia, creio que os principais setores da entidade defendem o sindicato como um importante espaço formativo. O sindicato tem um recorte sobre as condições econômicas da categoria profissional e suas relações no mundo do trabalho. Portanto, o sindicato, 'pode me chamar de dinossauro', deve ter ações formativas que esclareçam à categoria as bases da economia política. Isso não significa que o sindicato não deva investir em ações formativas relacionadas aos conhecimentos da profissão. Se nós somos educadores, temos que desmistificar as teorias que talvez não atendam aos interesses de nossos projetos de sociedade.

Convidada a manifestar-se, a pesquisadora disparou:

A SEE/SP prefere apostar nas iniciativas individuais, isto é, na busca pessoal do professor para resolução dos problemas enfrentados no exercício da profissão. Tal perspectiva alinha-se ao discurso contemporâneo no qual o professor torna-se agenciador da sua própria formação [...] O sindicato não deve ter o papel formativo de substituir o que as universidades não fizeram, o sindicato tem o papel de conscientizar a categoria acerca do papel político. Eles devem ter uma função agregadora.

Os depoimentos gravados e transcritos, após a interpretação do pesquisador, foram incorporados ao POETA:

Estranhamos o posicionamento da diretora de escola, pois nessa lógica, o Estado somente possui a obrigação de oferecer um programa de formação contínua para os professores, se forem exigidos resultados. Caso contrário, o poder público pode eximir-se de sua responsabilidade e jogá-la, totalmente, sobre os ombros dos professores. O representante da imprensa, além de esforços individuais, defendeu a existência de ações compensatórias de outras entidades sociais para suprimir as lacunas nas políticas de formação contínua. Se a formação oferecida pela SEE/SP é de baixa qualidade, segundo ele, o sindicato poderia oferecer ações formativas aos professores. A APEOESP ${ }^{6}$, como entidade social democrática, é formada por grupos divergentes que se organizam de acordo com suas convicções políticas. Muitas vezes, seus representantes apresentam posicionamentos antagônicos e contraditórios. Há pessoas que dizem que o sindicato não é lugar para ter formação, entretanto, o representante sindical analisa que os principais grupos da entidade defendem o sindicato como um importante espaço formativo. Porém, observa que o sindicato 'tem um recorte sobre as condições econômicas' da categoria 
profissional e suas relações no mundo do trabalho. Logo, nas suas palavras, o sindicato, 'pode me chamar de dinossauro', deve ter ações formativas que esclareçam o professorado sobre as bases da economia política e não um papel compensatório da aligeirada política formativa.

Segundo a pesquisadora, o sindicato não deve ter o papel formativo de substituir o que as universidades não fizeram. O sindicato tem o papel de conscientizar a categoria acerca do papel político, pois ela desconhece qualquer avanço nos direitos trabalhistas ou conquista de aumento salarial sem pressão sindical. Também, deve ter uma função agregadora, mesmo que os neoliberais tentem desqualificá-los, afirmando que são entidades corporativistas. O sindicalista lamenta que o sindicato não venha conseguindo atingir seu objetivo, pois quando vai às escolas para esclarecer os rumos da atual política, o professor tem uma postura "farinha pouca, meu pirão primeiro". Tal postura, segundo ele, é influência do modelo econômico neoliberal.

De qualquer forma, o representante sindical fez uma análise sobre esse movimento de corrida pela formação. Na sua visão, obrigar o professor a correr atrás da formação "é a típica frase do capitalismo". O discurso dos neoliberais é que a sociedade está mudando e você é "self made man", ou seja, faça-se por si mesmo. A responsabilização individual lança a "incompetência" do professor como principal suspeita pelo fracasso escolar nas redes de ensino, escondendo os reais problemas. Até porque competência no atual momento histórico significa ser competente para se adaptar à "nova" ordem econômica mundial, o neoliberalismo. Vale a pena relembrar que a individualização, como discutida nas páginas precedentes, apresenta-se como uma forte característica da sociedade pós-moderna e neoliberal contemporânea (Lippi, 2009, p. 176-177) ${ }^{7}$.

Além da confrontação ideológica que permitiu ao pesquisador reunir interpretações emitidas sobre outras interpretações, a realimentação do POETA deu-se, também, com as análises a partir do referencial teórico adotado.

Tanto a pesquisadora quanto o representante sindical apontam que a política curricular e formativa da rede estadual enquadra-se como uma política de aligeiramento, que pode ser induzida pela volatilidade das qualificações e funções requeridas pelo mercado de trabalho. Para Brzezinski (2008), o projeto neoliberal de educação alicerça-se na produção de saberes instrumentais e utilitários para a preparação de mão de obra. Dessa forma, sustentando uma "nova" teoria do capital humano, tal projeto ancora-se nas competências como eixo nos processos formativos. Por isso, críticos dessa pedagogia, entendem que "competências e habilidades" são uma "nova" roupagem com adornos da sociedade contemporânea para o "velho" tecnicismo pedagógico (Lippi, 2009, p. 149-150)

Para além das entrevistas e entrecruzamento das interpretações, o pesquisador percebeu que a compreensão sobre a política oficial de formação de professores no biênio 2008-2009 poderia ser aprofundada, caso fossem analisados os materiais audiovisuais utilizados durante os cursos oferecidos pela SEE/SP. 
Apesar das inovações tecnológicas, os mecanismos de interação virtual ainda não conseguem produzir situações semelhantes ao contato real. Também, temos clareza que nas políticas pedagógicas de cunho tecnicista, como esta que vem sendo desenhada, se entende que a comunicação e a interação entre os professores da rede seja desnecessária, pelo contrário, os tecnicistas preferem o isolamento, estratégia frequentemente utilizada por quem deseja o controle total das ações. Lembrando que um curso a distância com base em videoaulas e fóruns comporta uma formação de natureza centralizadora, pois são ínfimas as possibilidades de interação e interferência dos participantes. Assim formatados, os cursos a distância parecem pertencer a um movimento hegemônico contemporâneo de desqualificação do espaço social como contexto de interação ${ }^{8}$.

A concatenação das interpretações dos discursos contidos nos recursos pedagógicos com as opiniões dos participantes a respeito da sua utilização nas ações formativas realimentou o POETA, tornando possível, por exemplo, inferir sobre como os recursos audiovisuais se tornaram aparatos importantes na formação contínua de professores.

Ao analisarmos as videoaulas, enxergamos poucas possibilidades de discussão sobre a prática pedagógica, devido, principalmente ao formato do curso e dos cadernos dos professores (conteúdo desenvolvido), os quais foram organizados de maneira instrucional. Do ponto de vista concreto, ambos fornecem sequências didáticas para o trabalho do professor numa determinada perspectiva, o que não permite o diálogo ou a reflexão sobre as práticas escolares, cabendo ao participante a concordância com o exposto, o fazer por fazer ou a evasão. A intenção do curso, de fato, foi explicar aos professores uma proposta curricular elaborada pelos especialistas da universidade. A diretora de escola confirma nossa análise, pois, na sua visão os conteúdos foram 'bem a síntese dos cadernos', 'os professores que participaram acharam muito repetitivo em relação à apostila'.

Tal política restringiu o contato direto entre os professores da rede. Interpretando a utilização da Educação a Distância $(\mathrm{EaD})$ na formação docente, Brzezinski (2008) avalia que, contrariando o desejado, a modalidade, ao invés de procedimento complementar, transformou-se em substitutivo. Se o propósito era discutir melhor os materiais curriculares com os professores da rede, por que não foi empregada outra estratégia? Afinal, mesmo que a tecnologia da EaD 'democratize' o acesso, a sistemática utilizada limitou a interatividade entre os participantes do curso.

A SEE/SP reverbera o discurso hegemônico de que, na atualidade, não existe outra possibilidade de formar professores que não seja pela EaD. Depois que tais mecanismos foram criados, a própria secretaria fez proliferar a visão de que encontrar-se presencialmente é inútil, caro e improdutivo (Lippi, 2009, p. 194).

O POETA também foi entretecido com as análises de reportagens e artigos veiculados pela mídia impressa, pois, na opinião do pesquisador, certos veículos 
de grande penetração nos setores médios da população disseminavam princípios neoliberais que influenciavam a política de formação contínua de professores, por meio de uma campanha de desvalorização da educação pública.

Pesquisas sobre os rendimentos dos professores tiveram seus resultados selecionados por determinados grupos e, posteriormente, turbinados pela mídia conservadora ${ }^{9}$ com a intenção de divulgar que o professor da rede pública é bem remunerado quando comparado ao seu colega da rede privada, enquanto que a percepção social é justamente o contrário. Concretamente, não há qualquer esclarecimento de como esses resultados foram obtidos, todavia, foram divulgados como se fossem verdades absolutas ${ }^{10}$.

As análises do discurso midiático também foram entremeadas com as interpretações dos entrevistados na composição da versão final do POETA.

A SEE/SP ignora os horários coletivos na escola como espaços para a formação contínua, tornando-os um momento para socialização de informes sobre os projetos da SEE/SP e das Diretorias de Ensino. A pouca ou nenhuma importância dada aos horários coletivos foi expressa, segundo a pesquisadora entrevistada, pelo movimento que o Estado de São Paulo encabeçou para "melar" a lei que garantiria uma jornada mais digna aos professores, ou seja, o governador José Serra, sob alegações econômicas, exerceu pressão política para barrar a legislação que garantiria $1 / 3$ da jornada do professor para atividades de planejamento, formação e avaliação do processo educacional ${ }^{11}$. Isto demonstra que a SEE/SP reforça a posição evidente de conceber o professor como reprodutor de conceitos e conhecimentos selecionados previamente pelos órgãos centrais ofertados em programas formatados. Além disso, não reconhece os horários coletivos como espaço para a formação e para organização dos projetos pedagógicos da escola (Lippi, 2009, p. 165).

E:

A SEE/SP tem empregado discursos que desqualificam os professores, culpando-os pelos maus resultados nas avaliações externas e isentam o poder público e as instituições formadoras. De acordo com Paulo Renato Souza: 'Muitos professores propagam em sala de aula uma visão pouco objetiva e ideológica do mundo. Alguns não dominam sequer o básico das matérias e outros, ainda que saibam o necessário, ignoram as técnicas para passar o conhecimento adiante ${ }^{\prime 12}$. O sindicalista lembra que as políticas atuais condenam o profissional da educação que já foi punido anteriormente: 'O trabalhador foi lá, pagou para estudar à noite numa formação precária, é verdade, fez luta com aquela rede, se submeteu, esteve OFA ${ }^{13}$, passou no concurso, rachou, hoje ele é desvalorizado, porque dizem que ele não tem um bom trabalho'. O 'considerado' bom trabalho é associado à produtividade individual, ou seja, o professor só merece uma remuneração digna, caso apresente bons resultados em avaliações externas. Baseado em argumentos como esse o atual secretário busca legitimar a meritocracia como valor universal (Lippi, 2009, p. 179). 
A realimentação do POETA com as interpretações dos textos jornalísticos transmite ao leitor a impressão de que a mídia possuía uma parcela importante de responsabilidade sobre a disseminação e legitimação do discurso meritocrático na rede de ensino oficial. As análises dos editoriais da "Folha de São Paulo" realizadas pelo pesquisador concluíram que o jornal saiu em defesa das políticas estaduais que valorizavam uma educação escolar referendada pelo mérito individual. Esses argumentos fundamentaram-se, entre outros, no fato de que, segundo o pesquisador, o discurso da imprensa exaltou políticas educacionais como o bônus por resultado, o Índice de Desenvolvimento da Educação de São Paulo (IDESP) ${ }^{14}$, algumas ações do Plano de Desenvolvimento da Educação (PDE) ${ }^{15}$ e o plano de carreira estadual alicerçado no desempenho dos alunos nas provas oficiais ${ }^{16}$.

\section{Considerações}

Figura 01 - Movimentação do Pesquisador

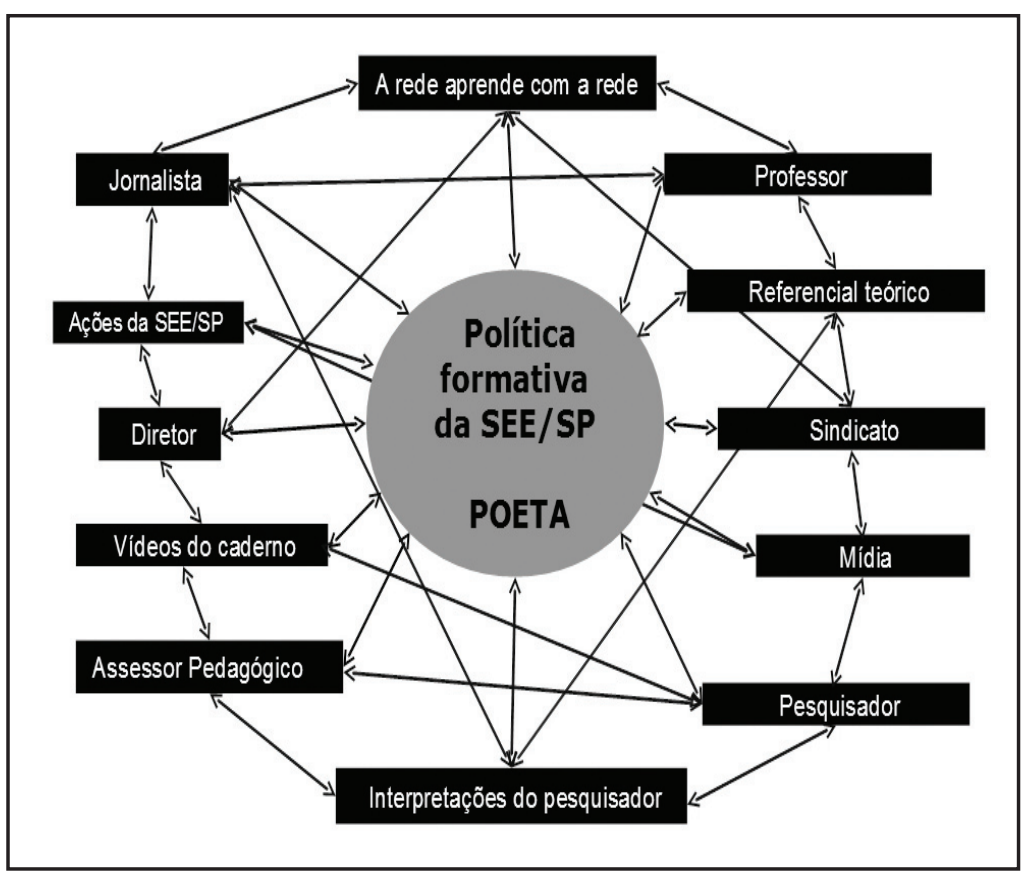

Fonte: elaboração dos autores.

A figura acima representa o movimento de ir e vir desenvolvido pelo pesquisador. A partir de excertos retirados do POETA, já repleto de interpretações anteriores, os participantes do estudo expressaram opiniões e apresentaram 
argumentos. Há que se ressaltar o esforço de interpretação crítica para costurar a colch a de retalhos representada pela constante interação entre o POETA e o circuito de realimentação exigido pela bricolagem. Nessa perspectiva, as interpretações não se esconderam sob o véu da neutralidade. A escrita do POETA foi influenciada, de forma decisiva, pela trajetória pessoal e profissional de quem investigou, pois, em semelhança ao que acontece com os demais participantes, o pesquisador construiu suas representações a partir dos discursos que acessou.

Os princípios democráticos explicitados no posicionamento político do pesquisador colidiram frontalmente com os posicionamentos que defenderam a política formativa investigada e ladearam as vozes críticas às ações oficiais, interpretadas como individualistas, meritocráticas e desmobilizadoras. Em momento algum, o pesquisador escondeu que a escolha dos excertos e o entretecimento das interpretações estavam embebidos nas próprias concepções, o que, obviamente, terminou por influir na versão final do POETA.

A bricolagem realizada não procurou elaborar uma explicação completa do fenômeno. O próprio autor se referiu ao estudo como uma interpretação provisória, transitória e em processo da política formativa da SEE/SP. As interpretações obtidas poderão, no presente ou no futuro, ser revisadas pelo próprio pesquisador ou por quem assim o deseje. O conhecimento produzido por meio da bricolagem não se escamoteia atrás de discursos de mérito científico e nem se rotula como universal. A bricolagem permite apresentar os conhecimentos elaborados com parcialidade, inserindo-os na complexidade contemporânea. Ela não se acovarda, traz à tona os percursos que delineou para a construção dos conhecimentos, assim como seus discursos adjacentes.

Após esmiuçarmos os pressupostos teóricos e os procedimentos adotados pela bricolagem, é possível afirmar que a preocupação com a democratização do processo de produção de conhecimentos é sua característica mais distintiva. Em uma pesquisa baseada na bricolagem, considerar os pontos de vista de todos os envolvidos é questão de honra, pois, ajuda a desconstruir as hierarquias de dominação e de subordinação entre grupos sociais, além de contribuir para a criação de alternativas coletivas ao desigual e excludente sistema social vigente.

Recebido em outubro de 2010 e aprovado em outubro de 2011.

\section{Notas}

1 A representação inclui as práticas de significação e os sistemas simbólicos por meio dos quais os significados são produzidos, posicionando cada pessoa como um sujeito. É por meio dos significados produzidos pelas representações que o homem e a mulher dão sentido à experiência e àquilo que são (Woodward, 2000, p. 17).

2 Desenvolvido na modalidade à distância, o curso pretendeu oferecer subsídios para os professores trabalharem em sintonia com a Proposta Curricular da SEE/SP. 
3 O termo foi utilizado propositalmente, pois os participantes do estudo exerciam diferentes papeis no processo.

4 Coordenadoria de Estudos e Normas Pedagógicas da Secretaria da Educação do Estado - órgão responsável pela elaboração da política de formação de professores da rede estadual paulista.

5 Fragmento extraído da primeira versão do POETA.

6 Sindicato dos Professores do Ensino Oficial do Estado de São Paulo.

7 Fragmento extraído da versão final do POETA.

8 Fragmento extraído de uma versão intermediária do POETA.

9 Referência ao artigo Professor não é coitado, publicado na revista Veja em 07 dez. 2007.

10 Fragmento extraído de uma versão intermediária do POETA.

11 São Paulo agora diz que lei federal da educação é inconstitucional, Folha de São Paulo, 09 out. 2008.

12 Entrevista do Secretário Estadual de Educação, revista Veja, 28 out. 2009.

13 Ocupante de Função Administrativa - nomenclatura atribuída ao professor temporário.

14 Nem meio caminho andado - editorial da Folha de São Paulo, 19 mar. 2009.

15 Piso de dignidade - editorial da Folha de São Paulo, 04 jul. 2008.

16 Valor ao mérito - editorial da Folha de São Paulo, 04 ago. 2009.

\section{Referências}

BERRY, Kathleen S. Estruturas da Bricolagem e da Complexidade. In: KINCHELOE, Joe L. e BERRY, Kathleen S. Pesquisa em Educação: conceituando a bricolagem. Tradução de Roberto Cataldo Costa. Porto Alegre: Artmed, 2007. P. 123-148.

COSTA, Marisa Vorraber; SILVEIRA, Rosa Hessel; SOMMER, Luis Henrique. Estudos Culturais, Educação e Pedagogia. Revista Brasileira de Educação, ANPED, n.23, p. 36-61, maio/ago. 2003.

DE CERTEAU, Michel. A Invenção do Cotidiano - artes de fazer. Tradução de Ephraim Ferreira Alves. Petrópolis: Vozes, 1994.

DENZIN, Norma K.; LINCOLN, Yvonna S. Introdução: a disciplina e a prática da pesquisa qualitativa. In: DENZIN, Norma K.; LINCOLN, Yvonna S. et al. O Planejamento da Pesquisa Qualitativa: teorias e abordagens. Tradução de Sandra Regina Netz. Porto Alegre: Artmed, 2006. P. 15-42.

DERRIDA, Jacques. A Estrutura, o Signo e o Jogo no Discurso das Ciências Humanas. In: DERRIDA, Jacques. A Escritura e a Diferença. Tradução de Maria Beatriz Nizza da Silva. São Paulo: Perspectiva, 1971. P. 229-249.

FROW, John; MORRIS, Meaghan. Estudos Culturais. In: DENZIN, Norma K.; LINCOLN, Yvonna S. et al. O Planejamento da Pesquisa Qualitativa: teorias e abordagens. Tradução de Sandra Regina Netz. Porto Alegre: Artmed, 2008. P. 315-344. 
GIROUX, Henry. Praticando Estudos Culturais nas Faculdades de Educação. In: SILVA, Tomas Tadeu da (Org.). Alienígenas na Sala de Aula: uma introdução aos Estudos Culturais em educação. Tradução de Tomaz Tadeu da Silva. Rio de Janeiro: Vozes, 2008. P. 85-103.

KINCHELOE, Joe L. Para além do Reducionismo: diferença, criticalidade e multilogicidade na bricolage e no pós-formalismo. In: PARASKEVA, João (Org.). Currículo e Multiculturalismo. Tradução de Helena Raposo e Manuel Alberto Vieira. Mangualde. Portugal: Edições Pedago, 2006. P. 63-93.

KINCHELOE, Joe L. Redefinindo e Interpretando o Objeto de Estudo. In: KINCHELOE, Joe L.; BERRY, Kathlenn S. Pesquisa em Educação: conceituando a bricolagem. Tradução de Roberto Cataldo Costa. Porto Alegre: Artmed, 2007. P. 101-122.

KINCHELOE, Joe L.; McLAREN, Peter. Repensando a Teoria Crítica e a Pesquisa Qualitativa. O Planejamento da Pesquisa Qualitativa: teorias e abordagens. Tradução de Sandra Regina Netz. Porto Alegre: Artmed, 2006. P. 281-314.

HALL, Stuart. Identidades Culturais na Pós-modernidade. Tradução de Tomaz Tadeu da Silva e Guacira Lopes Louro. Rio de Janeiro: DP\&A, 1997.

LARROSA, Jorge. Pedagogia Profana: danças, piruetas e mascaradas. Tradução de Alfredo Veiga-Neto. Belo Horizonte: Autêntica, 2006.

LÉVI-STRAUSS, Claude. O Pensamento Selvagem. Tradução de Maria Celeste da Costa e Souza e Almir de Oliveira Aguiar. São Paulo: Nacional, 1976.

LIPPI, Bruno Gonçalves. Formação Contínua de Professores de Educação Física no Estado de São Paulo: quais as políticas em jogo? 2009. Dissertação (Mestrado em Educação) - Programa de Pós-Graduação em Educação, Faculdade de Educação, Universidade de São Paulo, São Paulo, 2010.

McLAREN, Peter. Multiculturalismo Revolucionário: pedagogia do dissenso para novo milênio. Tradução de Márcia Moraes e Roberto Cataldo Costa. Porto Alegre: Artmed, 2000

MORIN, Edgar; ALMEIDA, Maria da Conceição de; CARVALHO, Edgar de Assis (Org.). Educação e Complexidade: os sete saberes e outros ensaios. Tradução de Edgard de Assis Carvalho. São Paulo: Cortez, 2002.

NELSON, Cary; TREICHLER, Paula A.; GROSSBERG, Lawrence. Estudos Culturais: uma introdução. In: SILVA, Tomas Tadeu da (Org.). Alienígenas na Sala de Aula: uma introdução aos Estudos Culturais em educação. Tradução de Tomaz Tadeu da Silva. Rio de Janeiro: Vozes, 2008. P. 07-38.

SANTOS, Boaventura de Sousa. Dilemas do Nosso Tempo: globalização, multiculturalismo e conhecimento. Entrevista concedida a Luís Armando Gandin e Álvaro Moreira Hypolito, Educação e Realidade, Porto Alegre, Universidade Federal do Rio Grande do Sul, v. 26, n. 1, p. 13-32, 2001

SILVA, Tomaz Tadeu da. Identidades Terminais: as transformações na política na pedagogia e na pedagogia na política. Petrópolis: Vozes, 1996.

SILVA, Tomaz Tadeu da (Org.). O que é, afinal, Estudos Culturais? Belo Horizonte: Autêntica, 2006.

WOODWARD, Kathryn. Identidade e Diferença: uma introdução teórica e conceitual. In: SILVA, Tomas Tadeu da (Org.). Identidade e Diferença: a perspectiva dos Estudos Culturais. Trad. Tomaz Tadeu da Silva. Petrópolis: Vozes, 2000. P. 07-72. 
Marcos Garcia Neira é professor do Departamento de Metodologia de Ensino da Faculdade de Educação da Universidade de São Paulo, em São Paulo. É licenciado em Educação Física e Pedagogia com Mestrado e Doutorado em Educação, Pós-doutorado em Currículo e Educação Física e Livre-Docência em Metodologia do Ensino de Educação Física. Orienta pesquisas em nível de iniciação científica, mestrado e doutorado. Investiga a prática pedagógica da Educação Física com apoio do CNPq. Tem experiência com os seguintes temas: Educação Física escolar, Currículo, Formação de professores, Estudos Culturais e Multiculturalismo.

E-mail: mgneira@usp.br

Bruno Gonçalves Lippi é coordenador pedagógico da rede municipal de São Paulo. Possui licenciatura em Educação Física pela Universidade Estadual Paulista Júlio de Mesquita Filho (UNESP, 2004). Especialização em Pedagogia do Esporte Escolar (FEF/Unicamp, 2007). Mestrado em Educação (FE/USP, 2010). Trabalhou como professor da rede municipal de São Caetano do Sul (2007-2011). Trabalhou como professor na rede estadual paulista (2005-2008). Tem experiência na área de Educação Física Escolar.

E-mail: bruno.lippi@uol.com.br 